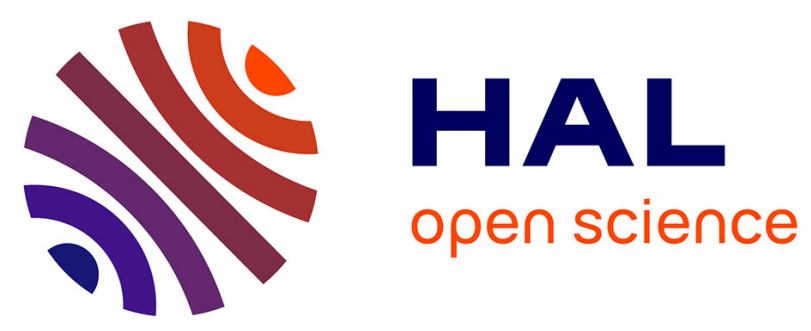

\title{
A new sensor for the evaluation of contact stress by inverse analysis during steel strip rolling
}

Daniel Weisz-Patrault, Alain Ehrlacher

\section{To cite this version:}

Daniel Weisz-Patrault, Alain Ehrlacher. A new sensor for the evaluation of contact stress by inverse analysis during steel strip rolling. Journal of Materials Processing Technology, 2011, 211 (9), pp.15001509. 10.1016/j.jmatprotec.2011.03.025 . hal-00595237

\section{HAL Id: hal-00595237 \\ https://hal.science/hal-00595237}

Submitted on 24 May 2011

HAL is a multi-disciplinary open access archive for the deposit and dissemination of scientific research documents, whether they are published or not. The documents may come from teaching and research institutions in France or abroad, or from public or private research centers.
L'archive ouverte pluridisciplinaire HAL, est destinée au dépôt et à la diffusion de documents scientifiques de niveau recherche, publiés ou non, émanant des établissements d'enseignement et de recherche français ou étrangers, des laboratoires publics ou privés. 


\title{
A new sensor for the evaluation of contact stress by inverse analysis during steel strip rolling
}

\author{
Daniel Weisz-Patrault ${ }^{\mathrm{a}}$, Alain Ehrlacher ${ }^{\mathrm{a}}$, Nicolas Legrand $^{\mathrm{b}}$ \\ ${ }^{a}$ Ecole Ponts ParisTech, UR Navier, 6 \& 8 Ave Blaise Pascal, 77455 Marne La Vallee, France \\ ${ }^{b}$ ArcelorMittal Dofasco, Research \& Development, Box 2460, 1330 Burlington St. E.Hamilton, Ontario L8N 3J5, Canada
}

\begin{abstract}
Knowledge of the contact stress between roll and strip becomes a critical factor in modern, high-speed rolling mills. In this paper, an inverse analytical method is developed to determine the contact stress in the roll gap by measuring the stress tensor with fibre optics at only one point inside the roll. Unlike many inverse methods, no matrix inversion is needed because the very small contact length would lead to ill-conditioned matrices. Iterative methods are also not studied because short computation times are desired. This approach uses the theory of elasticity on the assumption that the problem is isothermal and planar and relies on the expansion of holomorphic functions into a power series. On the other hand, the computation time is studied to rapidly optimise the industrial parameters during the rolling process. Hot, cold and temper-rolling simulations are given to demonstrate the accuracy of the method and the feasibility of this new kind of sensor, taking into account the restrictions (e.g., frequency of acquisition) of the local measurement system.
\end{abstract}

Keywords:

Steel rolling, Friction sensor, Free from damage, Computation time, Inverse analysis

\section{Introduction}

\subsection{Principles}

In steel rolling processes, two rolls are used as tools to reduce the thickness of a workpiece. Modern rolling mills combine higher rolling speeds, larger reductions, harder steel grades and thinner rolled strips. Thus, to ensure better product quality, especially in terms of thickness, flatness and defect-free surface, knowledge of friction and lubrication in the roll gap becomes critical. The contact between the strip and the roll is a location of unknown shear stress and normal pressure and lubrication conditions. Some models that characterise the interface taking into account lubrication have been proposed in recent years by Montmitonnet et al. (2007) but still need experimental validation. On the other hand, with industrial rolling process being currently dictated by empiricism, knowledge of the contact stress would be desirable to allow an optimisation of parameters such as speed and lubrication, with a closed-loop control.

Sensors already provide measurements of stress in the roll gap. Many investigators, such as Jeswiet and Rice (1982) or more recently, Liu et al. (2002) and Andersen et al. (2001), have used direct friction pin sensors. However, the presence of the pin disturbs the local lubricant flow at the interface, and the contact marks the strip; industrial use is therefore impossible. More recently, Lagergren et al. (2006) developed a sensor with a much bigger transducer than the strip-roll arc of contact. This sensor overcomes the difficulties of local perturbation of the frictional conditions, but the problem of strip marks is still unresolved.

Thus, an inverse method is necessary. Stelson (1983) showed that the roll itself can be used as a sensor by measuring the elastic deformation inside the roll (local sensor fully embedded) and by inferring the boundary stress by inverse analysis. The development of this new sensor aims for real-time measurement. Therefore, iterative schemes are not suitable. Moreover, a finite element approach, or any other method based on inversions of matrices (representing the relationship between the stress measured inside the roll and the contact stress), is not accurate. Because the roll gap has a very small length, this matrix is ill-conditioned because the angles involved in the matrix are too similar. Therefore, a problem arises whereby small measurement errors become strongly amplified, leading to poor accuracy. To avoid this classic problem, Meierhofer and Stelson (1987) proposed an analytical method based on the assumption that the problem is steady-state. Therefore, it is possible to measure the strain tensor (converted into stress by the equations of elasticity) at one point inside the roll, and the rotation 
of the roll allows a measurement of the whole circle. Therefore, it is possible to solve the problem bounded by the measurements (circle) and to extend the solution by continuity towards the roll gap. However, the method is based on an ineffective elastic approach that involves an expansion of the Airy potential into a power series (with additional terms) and an expansion of the stress measured inside the roll into a Fourier series. Then, an identification of the coefficients of both series is needed. To obtain enough equations, the authors used measurements on two concentric circles. They proposed measuring the stresses at two different points and at two different radii (which is technologically very difficult for industrial mills). Moreover, many inversions of matrices of identification (well-conditioned if the two radii are sufficiently distinct from each other) are needed.

Very recently, Legrand et al. (2010) computed this method and investigated its effectiveness by simulating several industrial conditions. The authors concluded that, for common industrial rolling conditions, the method developed by Meierhofer and Stelson (1987) is quite accurate but hardly usable because of the very long computation time. Moreover, the authors demonstrate that the contact stress cannot be reconstructed precisely under temper-rolling conditions (with extremely sharp stress gradients and a very short bite). It is demonstrated in this paper that the present method is successful under this kind of condition.

\subsection{Fibre optics}

In this paper, an analytical approach similar to the general approach of Meierhofer and Stelson (1987) is developed. The stress is measured only at one radius (instead of two). This difference is one of the main improvements because it is technologically much easier to insert one local strain sensor rather than two at different radii. Measurements of the whole circle are accomplished by the rotation of the roll. Concerning the local sensor itself, Meierhofer and Stelson (1987) used strain gages glued to the edge of the roll (considered thin enough). However, this technique is not recommended for industrial rolls because they are much larger than the strip. Therefore there is no strip-roll contact at the edge in the roll gap. Fibre optics are considered in this study; they rely on the principle of Bragg gratings and which give the local strains by interpreting the wavelengths as explained by Ferdinand et al. (2009). Fibre optics inserted in a thin radial hole in the roll is technologically possible. This technique is studied within the framework of the European project RFS-PR-08051. The surface of the roll is then re-manufactured to avoid any damage to the strip.

\subsection{Mathematical approach}

The problem bounded by the circle of measurements is solved. Then, the solution is extended by continuity to exhibit the contact stress in the roll gap. In this way, the equations of elasticity for an isotropic material under the isothermal assumption developed by Muskhelishvili (2008) are used. The complex formalism allows a very simple expansion of the holomorphic functions involved in the equations into power series. Moreover, a method to make the computation as fast as possible is demonstrated. Thus, the computation time has been considerably reduced to reach a real-time calculation of this new kind of sensor.

In this paper, all the results are derived from simulations. The following industrial conditions given by Legrand et al. (2010) are considered: hot rolling conditions, cold rolling conditions and temper-rolling conditions. Thus, the measurements at the inner radius are simulated by direct calculation (this part replaces the measurements provided by the fibre optics), and the contact stresses are inferred from the inverse method. Results are compared to the applied stress to estimate the accuracy of this new approach. The present method is more accurate than the previous one developed by Meierhofer and Stelson (1987). Moreover, Legrand et al. (2010) conclude that the extreme temper-rolling condition (or skinpass) cannot be reconstructed because of the extremely small contact length and very sharp stress gradients. In this paper, it is demonstrated that the reconstruction of these extreme rolling conditions is satisfactory.

\section{Inverse analysis}

The circle of measurements is denoted by $\partial C$ and its radius by $R_{c}$. The roll itself is denoted by $\partial \mathcal{D}$ and its radius by $R_{d}$. In the following derivation, the letter $c$ (resp $d$ ) means that the quantity is related to the circle $\partial C$ $(\operatorname{resp} \partial \mathcal{D})$. All the notations are listed in Table 1. 


\begin{tabular}{|ll|}
\hline$R_{d}$ & Outer radius (radius of the roll) \\
$R_{c}$ & Inner radius (radius of the measurements by fibre optics) \\
$N_{s}$ & Number of points of interpolation (cubic function) \\
$N_{m}$ & Number of measurement points \\
$N_{t}$ & Number of truncation (terms kept in the summation) \\
$N_{i n v}$ & Number of inversion of matrices \\
$\epsilon$ & Error of reconstruction \\
$\nabla_{\max }$ & Largest gradient in the inputs \\
$I_{\max }$ & Maximum of the norm of the input signal \\
$\delta$ & Angular part covered by the roll gap \\
\hline
\end{tabular}

Table 1: Nomenclature

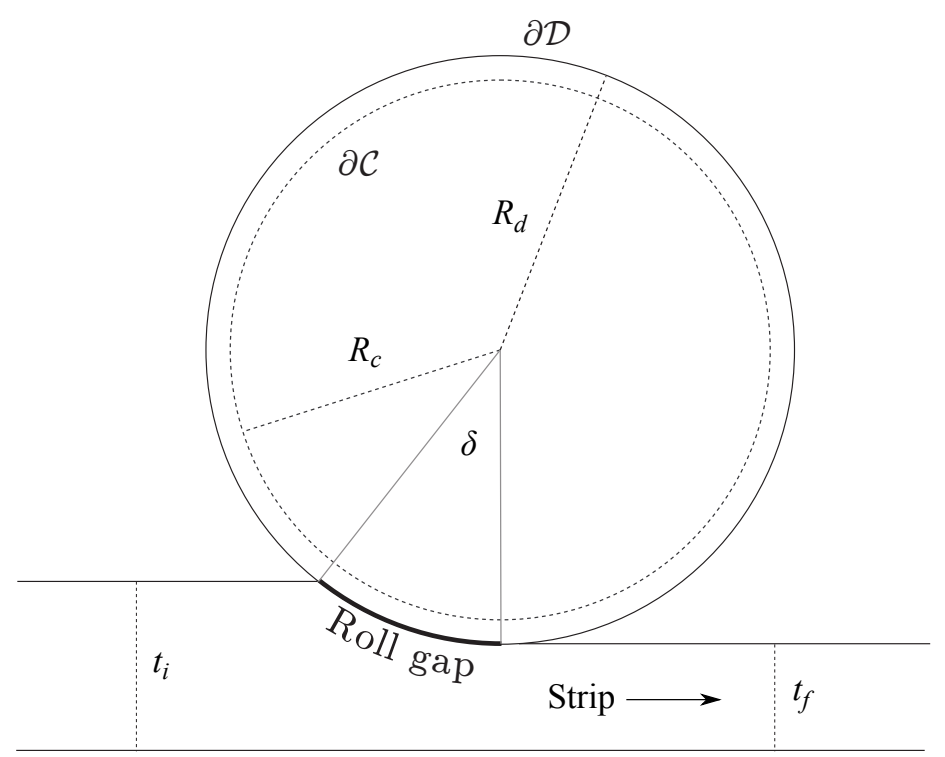

Figure 1: Stress measurement on $\partial C$

For all $z \in \mathbb{C}$, the equations of elasticity for an isotropic material under the isothermal assumption given by Muskhelishvili (2008) are:

$$
\left\{\begin{array}{l}
\sigma_{r r}+\sigma_{\theta \theta}=2(\Phi(z)+\overline{\Phi(z)}) \\
-\sigma_{r r}+\sigma_{\theta \theta}+2 i \sigma_{r \theta}=2 e^{2 i \theta}\left(\Psi(z)+\bar{z} \Phi^{\prime}(z)\right)
\end{array}\right.
$$

where $\Phi(z)$ and $\Psi(z)$ are unknown holomorphic functions defined on $\mathcal{D}$. Mathematically, these functions can be expanded into a power series. Therefore, for all $z \in \mathcal{D}$ :

$$
\Phi(z)=\sum_{k=0}^{+\infty} a_{k}^{\prime} z^{k} \mid \Psi(z)=\sum_{k=0}^{+\infty} b_{k}^{\prime} z^{k}
$$

For dimensionless coefficients, the following quantities are introduced:

$$
a_{k}=R_{c}^{k} a_{k}^{\prime} \mid b_{k}=R_{c}^{k} b_{k}^{\prime}
$$

By combining (1), (2) and (3), the stresses in the roll gap as a function of $\left(a_{k}\right)_{k \in \mathbb{N}}$ and $\left(b_{k}\right)_{k \in \mathbb{N}}$ are obtained:

$$
\left\{\begin{array}{l}
\sigma_{r r}^{d}+\sigma_{\theta \theta}^{d}=2 \sum_{k=0}^{+\infty}\left(\frac{R_{d}}{R_{c}}\right)^{k}\left(a_{k} e^{i k \theta}+\overline{a_{k}} e^{-i k \theta}\right) \\
-\sigma_{r r}^{d}+\sigma_{\theta \theta}^{d}+2 i \sigma_{r \theta}^{d}=2 \sum_{k=0}^{+\infty}\left(\frac{R_{d}}{R_{c}}\right)^{k}\left(b_{k} e^{i(k+2) \theta}+k a_{k} e^{i k \theta}\right)
\end{array}\right.
$$


By combining equations (4) $\sigma_{r r}^{d}, \sigma_{r \theta}^{d}$ and $\sigma_{\theta \theta}^{d}$ are obtained. Because

$$
\int_{\partial C} z^{k} d z= \begin{cases}2 i \pi & k=-1 \\ 0 & k \neq-1\end{cases}
$$

$\left(a_{k}\right)_{k \in \mathbb{N}}$ and $\left(b_{k}\right)_{k \in \mathbb{N}}$ are calculated by integrating the stresses measured at the inner radius using the following equations:

$$
\left\{\begin{array}{l}
a_{0}=\frac{1}{8 \pi} \int_{0}^{2 \pi} \sigma_{r r}^{c}+\sigma_{\theta \theta}^{c} d \theta \\
\forall k \in \mathbb{N}^{*} \\
a_{k}=\frac{1}{4 \pi} \int_{0}^{2 \pi} \frac{\sigma_{r r}^{c}+\sigma_{\theta \theta}^{c}}{e^{i k \theta}} d \theta \\
\forall k \in \mathbb{N} \\
b_{k}=\frac{1}{4 \pi} \int_{0}^{2 \pi} \frac{-\sigma_{r r}^{c}+\sigma_{\theta \theta}^{c}+2 i \sigma_{r \theta}^{c}}{e^{i(k+2) \theta}} d \theta-(k+2) a_{k+2}
\end{array}\right.
$$

\section{Accuracy and computation time}

The key to the whole method is the quality provided for the integrals (6). A small numerical error on $a_{k}$ or $b_{k}$ is multiplied at least by $\left(R_{d} / R_{c}\right)^{k}$, which increases until the solution diverges. Therefore, a truncation is needed. Thus, the more accurate the integrals are and the higher the progression is, the more accurate the solution is.

To compute an accurate integral, many measurement points are needed. However, the frequency of the measurement system is fixed to quite a low value, according to the frequency of acquisition (approximately $1 \mathrm{kHz}$ ) of new fibre optics. Hence, the number of points is limited. Because the measurement system and the rotation of the roll are not synchronised (and the problem is steady-state), it is possible to acquire signals from several rotations to increase the number of points. This technique is only used for extreme cases, such as temper-rolling conditions.

An effective way to calculate the integrals (6) (with a very short computation time) is to interpolate the input signal with a spline (cubic function). The number of interpolation points is called $N_{s}$ ( $s$ meaning spline). The choice of $N_{s}$ is a compromise between computation time and accuracy. The spline interpolation considerably improves the quality of the input signal. The integrations (6) are like Fourier coefficients, and a very effective way to compute these kinds of integrals is to use the fast Fourier transform (fft), which computes the Riemann sum from 1 to $N_{s}$ that converges to the integral.

More precisely, if $\sigma$ is the input signal represented as a column with $N_{s}$ rows, the fft classically computes the following vector $\left(\right.$ size $\left.N_{s}\right)$ :

$$
\frac{1}{N_{s}} \operatorname{fft}(\sigma)=\frac{1}{N_{s}}\left(\sum_{m=1}^{N_{s}} \sigma(k) e^{-2 i \pi \frac{(m-1)(k-1)}{N_{s}}}\right)_{k \in\left\|1, N_{s}\right\|} \underset{N_{s} \rightarrow+\infty}{\rightarrow}\left(\frac{1}{2 \pi} \int_{0}^{2 \pi} \sigma(\theta) e^{-i(k-1) \theta} d \theta\right)_{k \in\left\|1, N_{s}\right\|}
$$

Therefore, the extraction of the coefficients $a_{k}$ and $b_{k}$ can be done as follows:

$$
\left\{\begin{array}{l}
a_{0} \simeq \frac{1}{4 N_{s}} \mathrm{fft}\left(\sigma_{r r}^{c}+\sigma_{\theta \theta}^{c}\right)_{1} \\
\forall k \in \mathbb{N}^{*} \\
a_{k} \simeq \frac{1}{2 N_{s}} \mathrm{fft}\left(\sigma_{r r}^{c}+\sigma_{\theta \theta}^{c}\right)_{k+1} \\
\forall k \in \mathbb{N} \\
b_{k} \simeq \frac{1}{2 N_{s}} \mathrm{fft}\left(-\sigma_{r r}^{c}+\sigma_{\theta \theta}^{c}+2 i \sigma_{r \theta}^{c}\right)_{k+3}-(k+2) a_{k+2}
\end{array}\right.
$$

The Table 2 lists the CPU times corresponding to the computation of all the $N_{s}$ coefficients $a_{k}$ and $b_{k}$ (including the interpolation of the input signal) for different values of $N_{s}$. A linear dependence can be noted. All CPU times are obtained for a quadcore $2.8 \mathrm{GHz}$ and are the times displayed by Scilab 5.3. Moreover, a program compiled and translated in machine language would significantly reduce the computation time. 


\begin{tabular}{|c|c|}
\hline$N_{s}$ & CPU time (s) \\
\hline 20000 & 0.01 \\
\hline 50000 & 0.03 \\
\hline 100000 & 0.06 \\
\hline 200000 & 0.12 \\
\hline
\end{tabular}

Table 2: CPU time

In the following, the parameter $N_{s}$ is fixed to 100000 . This choice is related to the accuracy needed for the reconstruction and is discussed in section 6.

Formula (4) is a deconvolution and could be computed with the ifft (inverse fast Fourier transform). However, the ifft does not offer the choice of the reconstruction points. Because the reconstruction is only needed in the roll gap, the deconvolution is computed as follows. Formula (4) is rewritten in matrix form. Matrices are underlined twice and vectors are underlined once. Therefore, if the reconstruction is done for $N_{r}$ points in the roll gap ( $r$ meaning reconstructed) called $\left(\theta_{j}\right)_{j \in\left\|1, N_{r}\right\|}$ and if the number of terms kept in the sum is called $N_{t}(t$ meaning truncation):

$$
\left\{\begin{array}{l}
\frac{\sigma_{r r}^{d}}{}+\underline{\sigma_{\theta \theta}^{d}}=\underline{\underline{\mathcal{M}_{1}}} \cdot \underline{A}+\underline{\underline{\mathcal{M}_{1}}} \cdot \underline{\bar{A}} \\
\underline{\sigma_{r r}^{d}}+\underline{\sigma_{\theta \theta}^{d}}+2 i \sigma_{r \theta}^{d}=\underline{\underline{\mathcal{M}_{2}}} \cdot \underline{B}+\underline{\underline{\mathcal{M}_{3}}} \cdot \underline{A}
\end{array}\right.
$$

where :

$$
\left\{\begin{array}{l}
\underline{\underline{\mathcal{M}_{1}}}=2\left(\left(\frac{R_{d}}{R_{c}}\right)^{k} e^{i k \theta_{j}}\right)_{(j, k) \in\left\|1, N_{r}\right\| x\left\|1, N_{t}\right\|} \\
\underline{\underline{\mathcal{M}_{2}}}=2\left(\left(\frac{R_{d}}{R_{c}}\right)^{k} e^{i(k+2) \theta_{j}}\right)_{(j, k) \in\left\|1, N_{r}\right\| x\left\|1, N_{t}\right\|} \\
\underline{\underline{\mathcal{M}_{3}}}=2\left(\left(\frac{R_{d}}{R_{c}}\right)^{k} k e^{i k \theta_{j}}\right)_{(j, k) \in\left\|1, N_{r}\right\| x\left\|1, N_{t}\right\|}
\end{array}\right.
$$

and $\underline{A}=\left(a_{k}\right)_{k \in\left\|1, N_{t}\right\|}$ and $\underline{B}=\left(b_{k}\right)_{k \in\left\|1, N_{t}\right\| \cdot}$.

Table 2 gives the CPU times to calculate $\underline{A}$ and $\underline{B}$. A very interesting point in writing (4) in matrix form is that the matrices $\mathcal{M}_{1}, \mathcal{M}_{2}$ and $\mathcal{M}_{3}$ can be calculated before the rolling process and can be stocked in a library. The on-line computation is therefore limited to the products involved in (9). This library can contain different versions of the matrices corresponding to different values of $N_{r}$ and $N_{t}$. The computation can be adaptive. The CPU time of the products in (9) for $N_{r}=55$, which is enough for an industrial interpretation, is $0.002 \mathrm{~s}$.

\section{Error estimate}

To evaluate the quality of the reconstruction, a quantified error estimate is needed. The relative distance (norm 2) between the reconstructed stress $\sigma^{r}$ and the applied stress $\sigma^{a}$ (where $r$ means reconstructed and $a$ means applied) is introduced:

$$
\epsilon=\sqrt{\frac{\int_{0}^{2 \pi}\left(\sigma^{r}(\theta)-\sigma^{a}(\theta)\right)^{2} d \theta}{\int_{0}^{2 \pi} \sigma^{a}(\theta)^{2} d \theta}}
$$

Thus, $\epsilon$ is dimensionless and can be understood as a percentage.

\section{Truncation criterion}

The effectiveness of the method relies on the integrations (6). A small mistake (unavoidable) is multiplied at least by $\left(R_{d} / R_{c}\right)^{k}$, which becomes higher and higher until that the solution diverges. Therefore, a truncation of the development is needed. The number of terms kept in the sum is called $N_{t}$ ( $t$ meaning truncation). A method to make a good guess of $N_{t}$ according to some parameters of input signals is proposed.

Input signals are given with a resolution called $N_{m}$, which represents the number of measurement points on $2 \pi$ ( $m$ meaning measured). The quality of the extraction of the coefficients $a_{k}$ and $b_{k}$ depends highly on $N_{m}$ and 
on the singularity of the signal. In this paper, the largest stress gradient in the signal (called $\nabla_{\max }$ ), the maximum of the norm of the signal (called $I_{\max }$ ) and the angular part covered by the roll gap (called $\delta$ ) are considered to characterise the singularity of the signal.

A very classic model is a logarithmic law:

$$
N_{t}=\mathcal{A} \times N_{m}^{\alpha} I_{\text {max }}^{\beta} \nabla_{\text {max }}^{\gamma} \delta^{\lambda}
$$

where $\alpha, \beta, \gamma$ and $\lambda$ are dimensionless coefficients. Moreover, $\nabla_{\max }^{\beta} I_{\max }^{\gamma} \delta^{\lambda}$ should be dimensionless, therefore $\beta=-\gamma=-\lambda$. Thus, the model becomes:

$$
N_{t}=\mathcal{A} \times N_{m}^{\alpha} \mathcal{S}^{\beta}
$$

where : $\mathcal{S}=I_{\max } /\left(\nabla_{\max } \delta\right)$

This model is a rule of thumb. A systematic study of the order of convergence of the integration method proposed in section 3 would be necessary for a theoretical analysis of the number of truncations $N_{t}$. However, such a theoretical point of view is not needed for the purpose of this discussion. An estimate of the number of truncations is sufficient to obtain a reconstruction as close as possible to the best reconstruction depending on the input signal.

To determine $\mathcal{A}, \alpha$ and $\beta$, three industrial rolling conditions taken from Legrand et al. (2010) are tested. Hot rolling conditions, cold rolling conditions and temper-rolling conditions cover the range of the possible signals during industrial rolling processes. For that reason, this set of cases is used as a reference. The stress profiles in the roll gap are known, and a direct elastic calculation is performed to obtain the stress profiles at the inner radius (assumed to be measured by fibre optics). These stress profiles are the inputs of the inverse method. By using (11), it is possible for each rolling condition and each value of $N_{m}$ to plot the error between the reconstructed stress and the applied stress against the number of truncation $N_{t}$. For example, Figure 2 (corresponding to the normal pressure of the cold rolling condition with $N_{m}=1000$ ) shows that the error reaches a minimum for a unique value of $N_{t}$. It is clear that the best reconstruction is a compromise between the convergence of the series and the amplified error of integration. The reconstructions corresponding to three values of $N_{t}$ are given in Figures 3, 4 and 5. Fig. 3 is a bad reconstruction due to the fact that the series have not converged, Fig. 4 is the best reconstruction and Fig. 5 is a bad reconstruction due to the fact that too many terms with amplified errors are kept in the sums. The value of $N_{t}$ that corresponds to the best reconstruction is listed in Tables 3 and 4 for different values of $N_{m}$ and for the three rolling conditions (i.e., different values of $\mathcal{S}$ ).

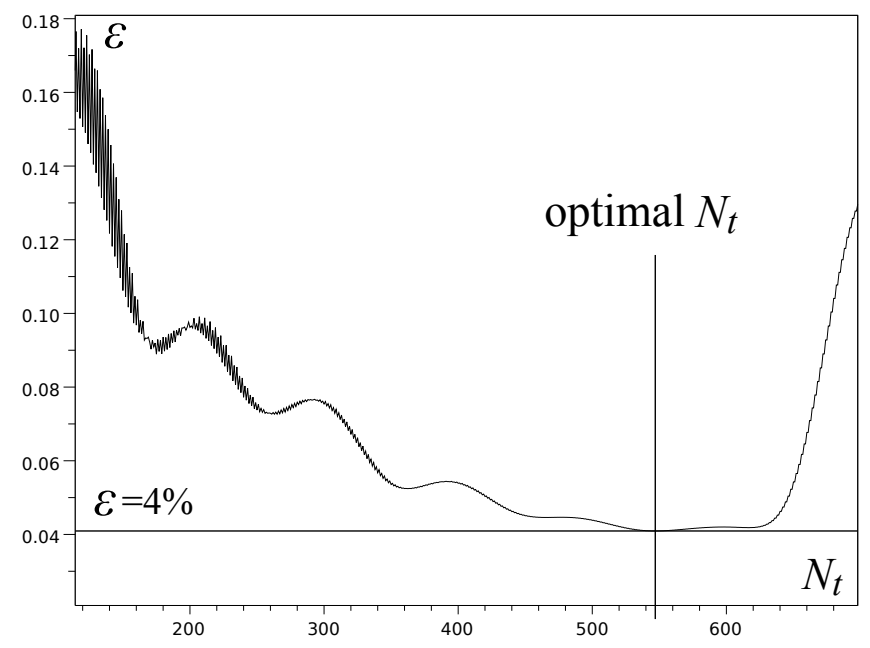

Figure 2: $\epsilon$ against $N_{t}$ 


\begin{tabular}{|c|c|c|c|}
\hline$N_{m}$ & $\begin{array}{c}\text { Hot rolling } \\
\mathcal{S} \simeq 0.07\end{array}$ & $\begin{array}{c}\text { Cold rolling } \\
\mathcal{S} \simeq 0.39\end{array}$ & $\begin{array}{c}\text { Temper-rolling } \\
\mathcal{S} \simeq 0.64\end{array}$ \\
\hline 1000 & $\mathbf{4 4 5}$ & $\mathbf{5 4 4}$ & $\mathbf{6 3 0}$ \\
\hline 1250 & $\mathbf{5 0 3}$ & $\mathbf{7 0 8}$ & $\mathbf{8 9 9}$ \\
\hline 1500 & $\mathbf{5 3 2}$ & $\mathbf{8 4 6}$ & $\mathbf{1 1 1 9}$ \\
\hline 2000 & 532 & $\mathbf{1 0 8 0}$ & $\mathbf{1 3 0 4}$ \\
\hline 3000 & 532 & 1080 & $\mathbf{1 4 2 8}$ \\
\hline 5000 & 532 & 1080 & $\mathbf{2 6 0 0}$ \\
\hline
\end{tabular}

Table 3: Optimal $N_{t}$ for normal pressure

\begin{tabular}{|c|c|c|c|}
\hline$N_{m}$ & $\begin{array}{c}\text { Hot rolling } \\
\mathcal{S} \simeq 0.087\end{array}$ & $\begin{array}{c}\text { Cold rolling } \\
\mathcal{S} \simeq 0.29\end{array}$ & $\begin{array}{c}\text { Temper-rolling } \\
\mathcal{S} \simeq 0.3\end{array}$ \\
\hline 1000 & $\mathbf{4 3 7}$ & $\mathbf{5 2 7}$ & $\mathbf{5 9 0}$ \\
\hline 1250 & $\mathbf{4 8 9}$ & $\mathbf{6 3 0}$ & $\mathbf{9 1 9}$ \\
\hline 1500 & $\mathbf{5 0 6}$ & $\mathbf{7 6 1}$ & $\mathbf{7 9 5}$ \\
\hline 2000 & 506 & $\mathbf{9 6 0}$ & $\mathbf{1 1 5 0}$ \\
\hline 3000 & 506 & 960 & $\mathbf{1 6 2 0}$ \\
\hline 5000 & 506 & 960 & $\mathbf{2 3 6 4}$ \\
\hline
\end{tabular}

Table 4: Optimal $N_{t}$ for shear stress

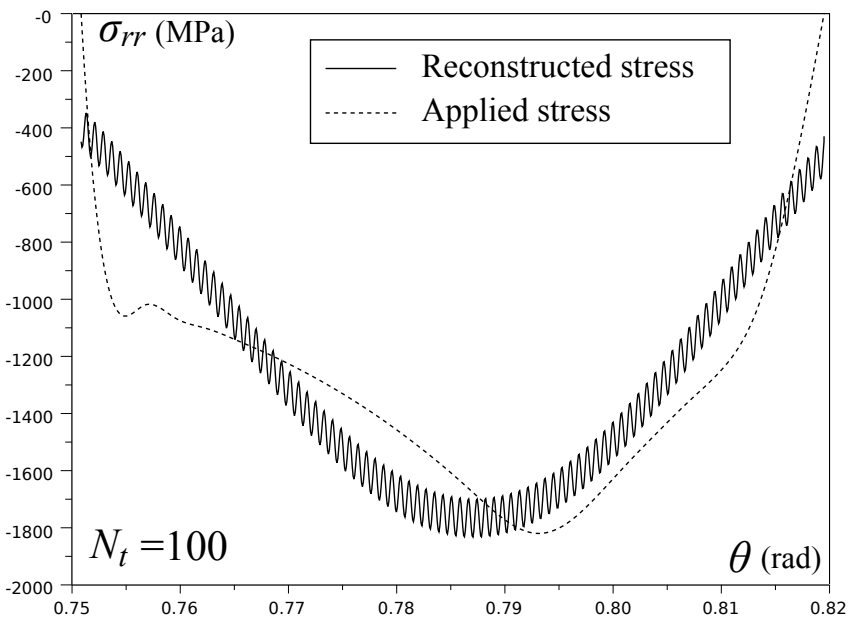

Figure 3: Reconstruction for cold rolling conditions with $N_{m}=1000$ and $N_{t}=100$ 


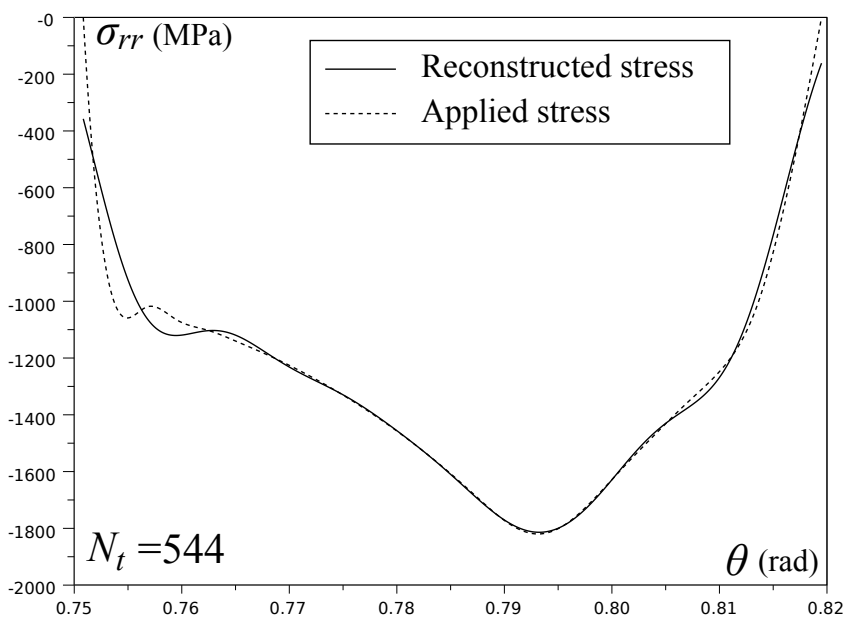

Figure 4: Reconstruction for cold rolling conditions with $N_{m}=1000$ and $N_{t}=544$

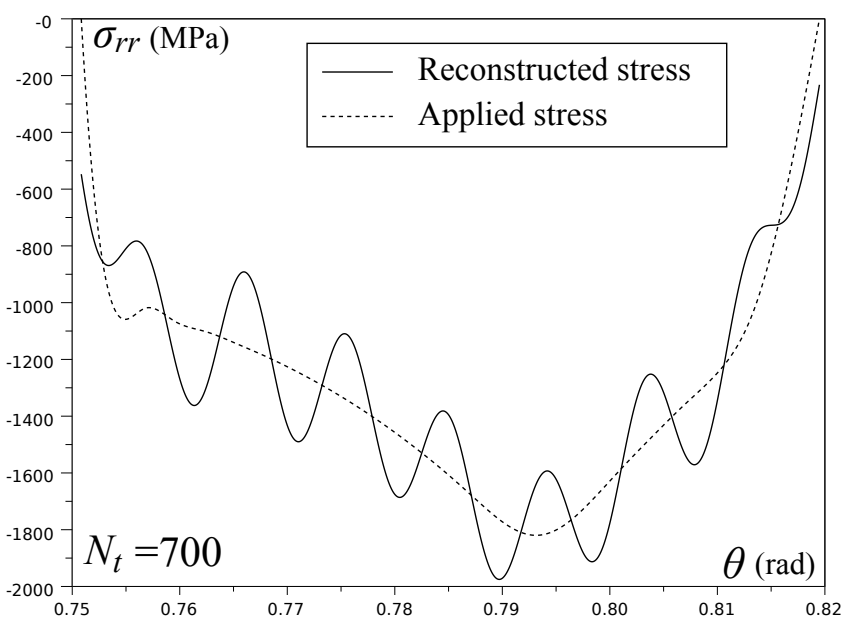

Figure 5: Reconstruction for cold rolling conditions with $N_{m}=1000$ and $N_{t}=700$

In Tables 3 and 4, the optimal number of truncations $N_{t}$ reach a limit when $N_{m}$ increases. Because of the spline interpolation (with a very large number of interpolation points) and the regularity of input signals, the precision of the integrations cannot be improved beyond a limit, depending on the length of the roll bite. To identify the constants $\mathcal{A}, \alpha$ and $\beta$ involved in the logarithmic model (13), only the values of $N_{t}$ before the saturation are taken into account (values in bold letters in Tables 3 and 4). The validity of this model is therefore limited to values of $N_{m}$ for which the precision is not saturated.

In Figure 6, the optimal numbers of truncation $N_{t}$ from the Tables 3 and 4 are represented against $N_{m} \mathcal{S}^{\frac{\beta}{\alpha}}$. The model (13) is also represented with the following values:

$$
\left\{\begin{array}{l}
\mathcal{A}=1.83 \\
\alpha=0.86 \\
\beta=0.215
\end{array}\right.
$$




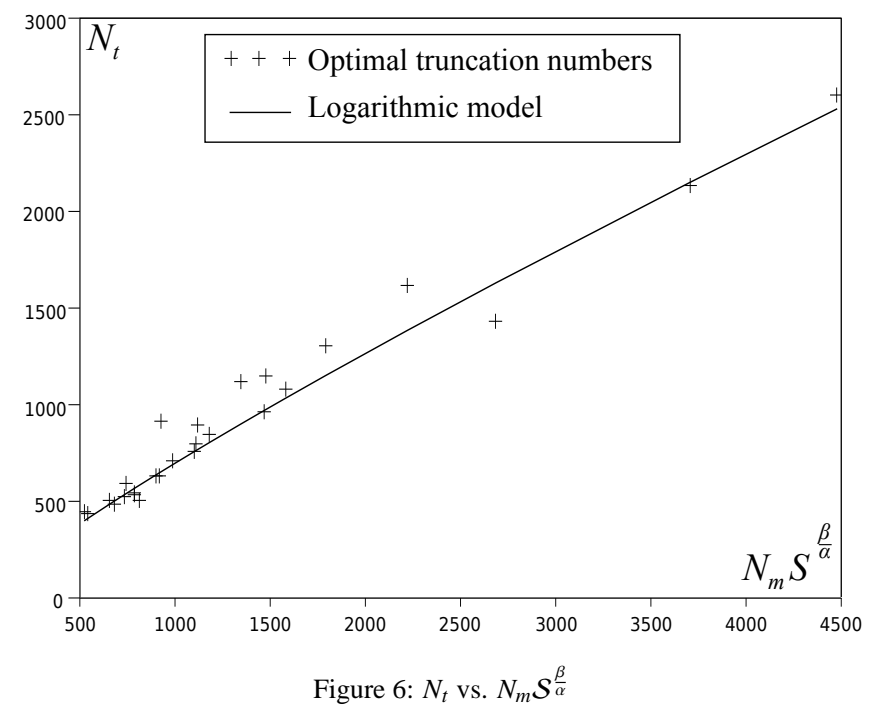

The CPU time of the logarithmic model (13) is $0.006 \mathrm{~s}$.

\section{Discussion on $N_{s}$}

In this section, the choice of the number of interpolation points $N_{s}=100000$ is discussed. As explained in section 3, this choice is a compromise between accuracy and computation time. By using the error estimate (11) and the three industrial rolling conditions taken from Legrand et al. (2010), the stresses for different values of $N_{s}$ (i.e., different qualities of integration) are reconstructed. Therefore, it is possible to plot the error between the reconstruction and the applied stress against the number of interpolation points $N_{s}$ for each rolling condition. Figure 7 (resp 8) presents the error against $N_{s}$ for the reconstruction of normal pressure (resp shear stress). The values of $N_{m}$ are the ones considered in the following sections. For temper-rolling conditions, the error decreases exponentially when $N_{s}$ increases. The choice that is the best compromise between accuracy and computation time is $N_{s}=100000$. For simplicity, this choice is applied for all rolling conditions, but for industrial use, hot and cold rolling conditions can be calculated even faster by using $N_{s}=20000$, for example.

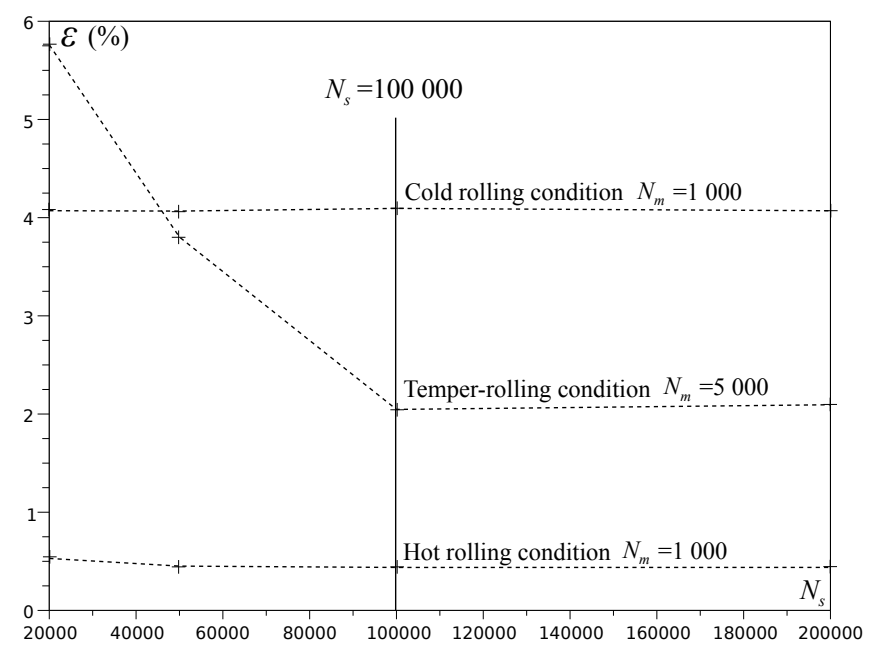

Figure 7: $\epsilon$ vs. $N_{s}$ for normal pressures $\left(\sigma_{r r}\right)$ 


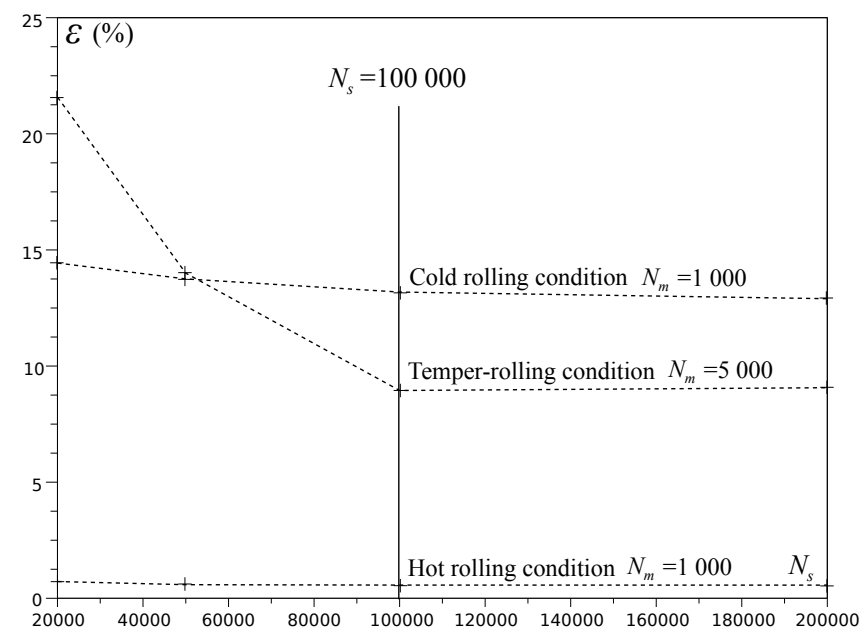

Figure 8: $\epsilon$ vs. $N_{s}$ for shear stress $\left(\sigma_{r \theta}\right)$

\section{Validation and comparison}

\subsection{Stress in the roll gap: applied stress}

The three industrial rolling conditions used in sections 5 and 6 are used for the quantitative validation of the inverse method presented here and for comparison with the results obtained by Legrand et al. (2010). The contact stress of the three rolling conditions is given by a numerical model, LAM3 edited by Hacquin (1996). The stress profiles for normal pressure $\left(\sigma_{r r}\right)$ and shear stress $\left(\sigma_{r \theta}\right)$ are given in Figures 9, 10 and 11. Hot rolling conditions are the least singular, and temper-rolling conditions are the most singular. The roll gap lengths are around 71.6 $\mathrm{mm}$ for hot rolling conditions, $13.7 \mathrm{~mm}$ for cold rolling conditions and $4.8 \mathrm{~mm}$ for temper-rolling conditions. It is interesting to note that the shape of the stresses given by the model LAM3 Hacquin (1996) bear a resemblance to the contact stresses found by Boussinesq (1885) for a concentrated load on a semi-infinite half plane with the classic change of sign of the shear stress.

Hot (resp cold and temper) rolling simulation settings are given in Table 5 (resp Tables 6 and 7).

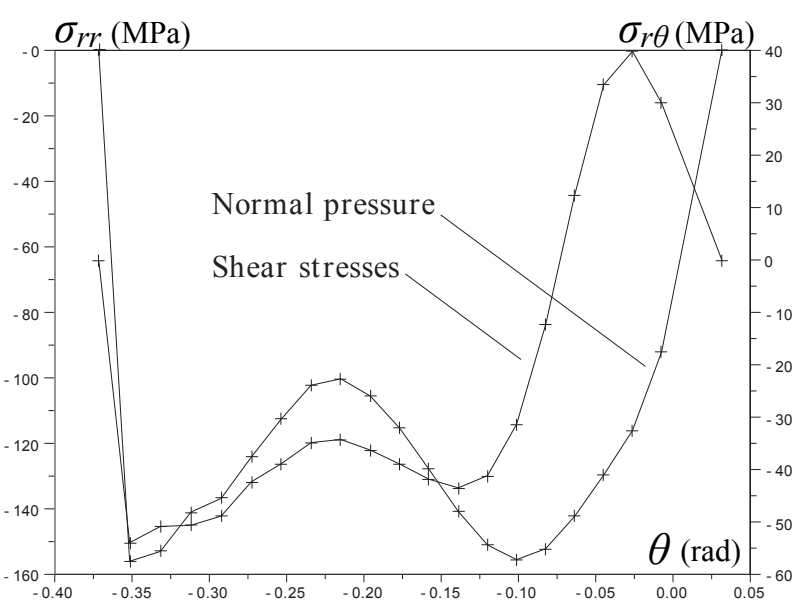

Figure 9: Contact stresses for hot rolling 


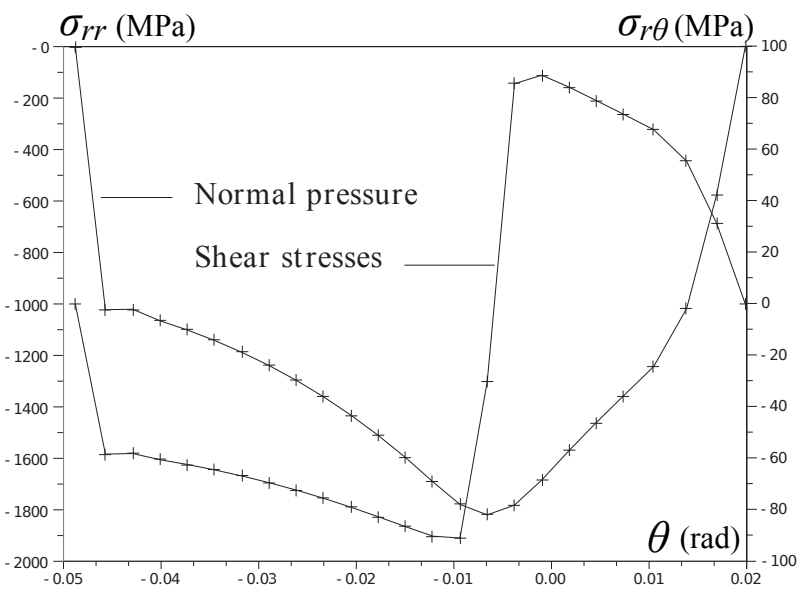

Figure 10: Contact stresses for cold rolling

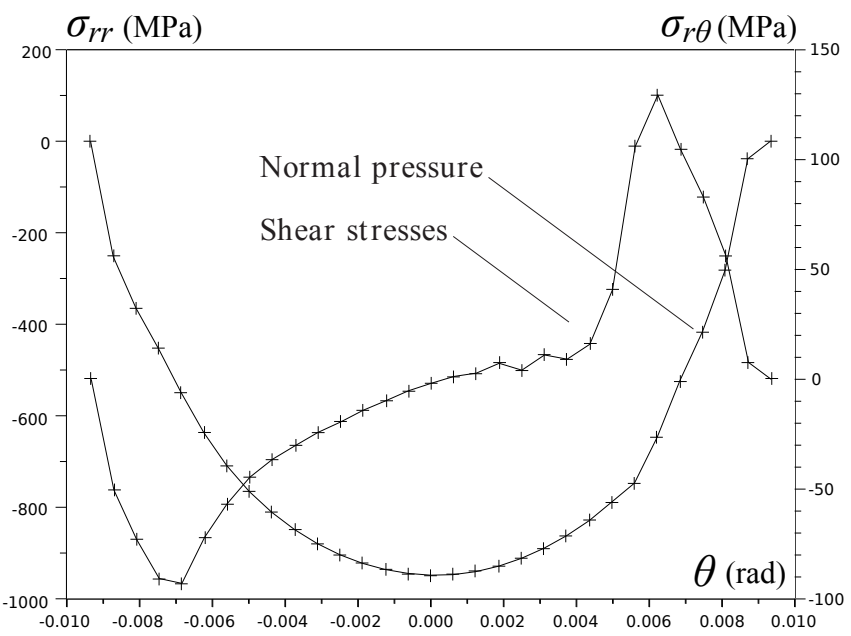

Figure 11: Contact stresses for temper-rolling

\subsection{Simulated measurements}

A direct elastic calculation gives the stresses at the radius $R_{c}$ (considered as a simulation of the measurements that would be done with fibre optics). In Figures 12, 13 and 14, the stresses calculated at $R_{c}$ without noise are given. The data are not experimental results but rather calculations.

The inner radius $R_{c}$ is chosen at $3 \mathrm{~mm}$ from the surface of the roll for hot and cold rolling conditions, which is technologically a correct distance. For temper-rolling conditions, the stress gradients are very sharp, and $R_{c}$ is chosen at only $2 \mathrm{~mm}$ from the surface of the roll, which is the closest distance at which the fibre optics can be accurately inserted. Legrand et al. (2010) show that a reconstruction is impossible for temper-rolling conditions because the authors require an input signal at $1 \mathrm{~mm}$ from the surface of the roll, which is not technologically possible. In this paper, this difficulty is overcome.

It is also important to remember that the number of points $N_{m}$ is chosen to be consistent with the quite low frequency of acquisition $(1 \mathrm{kHz})$. With a typical experimental speed $(1 \mathrm{cycle} / \mathrm{sec})$, the resolution is $N_{m}=1000$ points for $2 \pi$. This resolution is used for hot and cold rolling conditions.

For industrial speeds, measurements on several rotations are necessary to reach this kind of resolution because the acquisition system and rotation speed are not synchronised. This technique is used for the temper-rolling condition because of the very small contact length. Three cycles are considered (i.e, $N_{m}=3000$ ) followed by five cycles (i.e, $N_{m}=5000$ ). 


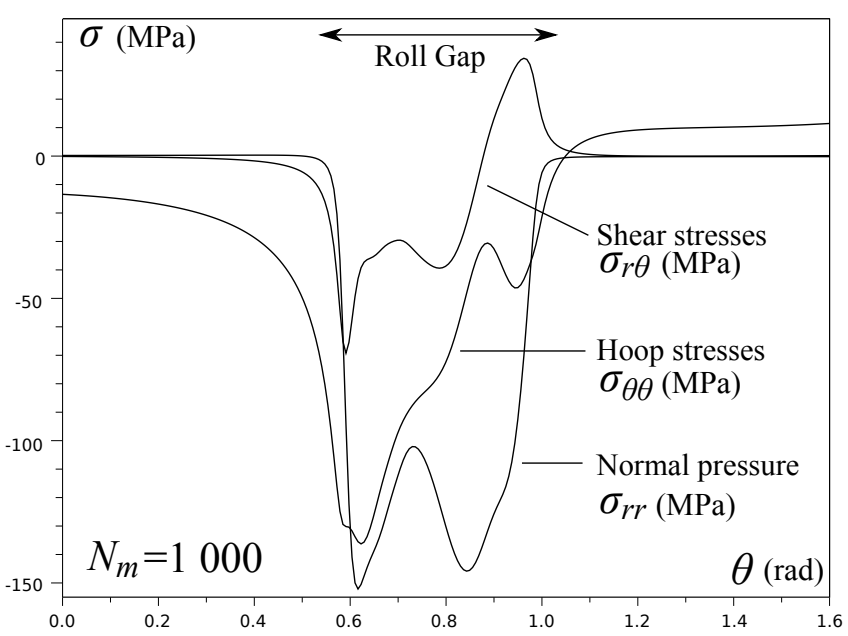

Figure 12: Stresses calculated at $R_{c}$ for hot rolling

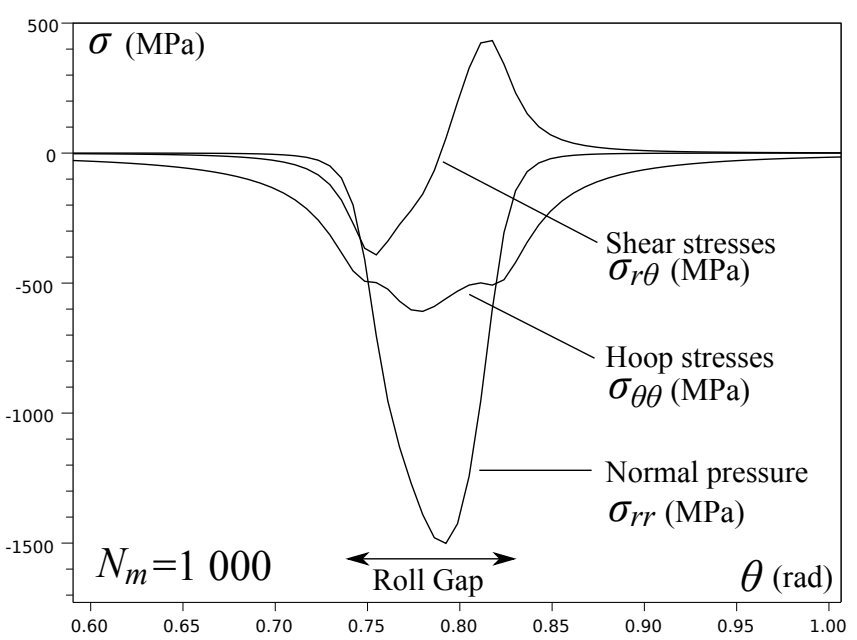

Figure 13: Stresses calculated at $R_{c}$ for cold rolling

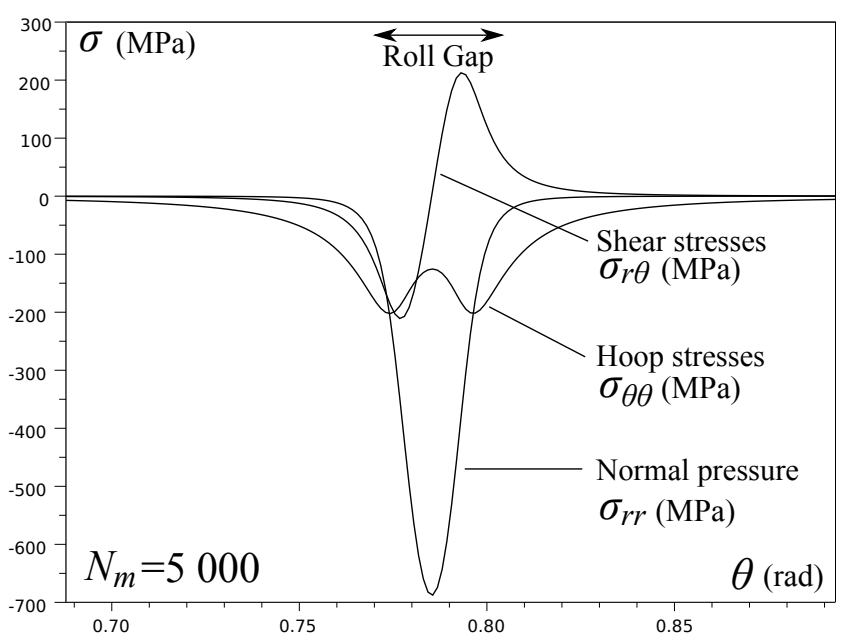

Figure 14: Stresses calculated at $R_{c}$ for temper-rolling 


\subsection{Results without noise}

The inverse method is applied, and a comparison between the reconstruction of the contact stress and the applied stress is made. Results given by Legrand et al. (2010) are also compared. Results corresponding to the three rolling conditions (with different options discussed in the following) are given in Figures 15 to 22.

The number of truncations is chosen according to the approximate (but predictive) model (13). Therefore, the results do not correspond to the best possible reconstruction.

\subsubsection{Hot rolling}

The problem is assumed to be isothermal. However, for hot rolling conditions, the thermal stress is not negligible, as demonstrated by Legrand et al. (2010). In this paper, this aspect is not studied (the thermal stress is neglected), but the difficulty is overcome in a future publication where the thermal problem is solved. Thus, the coupled thermal and mechanical problems overlap by linearity.

Figures 15 and 16 are relative to hot rolling conditions. The truncation is done at the 399th harmonic for $\sigma_{r r}$ (and at the 412-th for $\sigma_{r \theta}$ ). The results in Figures 15 and 16 show that the reconstructed stress (with the present method) and the applied stress are almost identical. Therefore, the new method developed in this study is much more accurate than the computation of Legrand et al. (2010) (based on the work of Meierhofer and Stelson (1987)). The neutral point is very well predicted, which is an important result for industrial studies .

All simulation parameters and the reconstruction errors in percentage and indicative computation time of both methods are listed in Table 5. The time of the computation of Legrand et al. (2010) is an estimate from CPU times obtained with a dualcore $2 \mathrm{GHz} . N_{i n v}$ is the number of inversions of matrices of identification $(4 \times 4)$, the present study does not involve any matrix inversion.

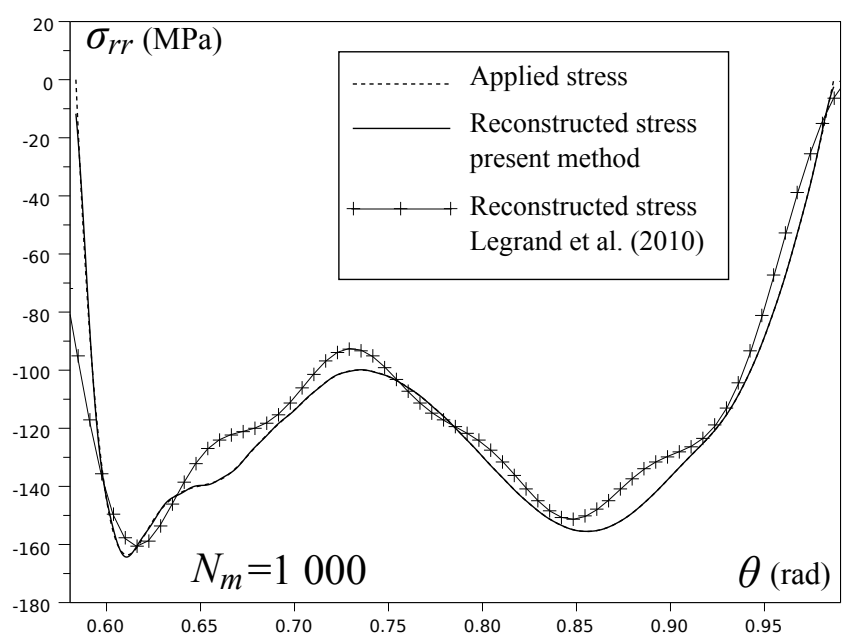

Figure 15: Results for hot rolling without noise, $\sigma_{r r}$ 


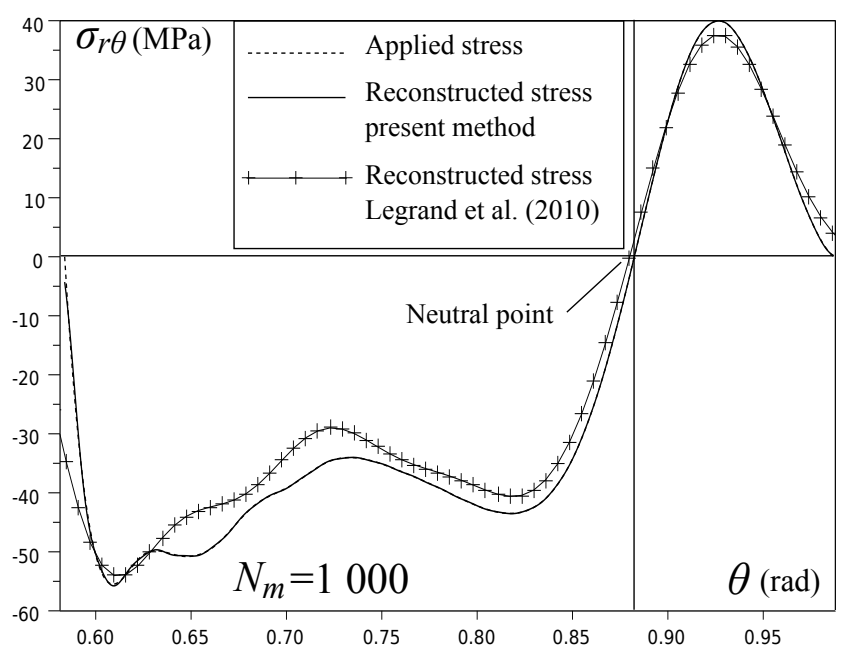

Figure 16: Results for hot rolling without noise, $\sigma_{r \theta}$

\begin{tabular}{|l|c|c|}
\hline & $\begin{array}{c}\text { Legrand et al. (2010) } \\
(r r / r \theta)\end{array}$ & $\begin{array}{c}\text { Present study } \\
(r r / r \theta)\end{array}$ \\
\hline$R_{d}(\mathrm{~mm})$ & 177.51 & 177.51 \\
\hline$R_{c}(\mathrm{~mm})$ & 174.51 & 174.51 \\
\hline$N_{t}$ & 100 & $(399 / 412)$ \\
\hline$N_{m}$ & 1000 & 1000 \\
\hline$N_{i n v}$ & 200 & 0 \\
\hline$\epsilon(\%)$ & $(9.3 / 13.2)$ & $(0.63 / 0.75)$ \\
\hline CPU time $(\mathrm{s})$ & $\simeq 300$ & $\simeq 0.07$ \\
\hline
\end{tabular}

Table 5: Hot rolling summary

\subsubsection{Cold rolling}

For cold rolling conditions the thermal stress is more negligible than for hot rolling conditions, as demonstrated by Legrand et al. (2010). The truncation is done at the 568th harmonic for $\sigma_{r r}$ (and at the 534th for $\sigma_{r \theta}$ ). As for the hot rolling conditions, the results in Figures 17 and 18 show that the new inverse method is more accurate than the computation of Legrand et al. (2010) (based on the work of Meierhofer and Stelson (1987) ). Computation time is extremely reduced compared to the work of Legrand et al. (2010).

For cold rolling conditions, there is Coulomb-type friction with a discontinuity of the shear stress at the neutral point (where the sliding speed between the roll and the strip changes sign). For hot rolling conditions, there is an area around the neutral point where the roll and the strip do not slide over each other. In this area, the shear stress can be arbitrary compared to the normal pressure.

It is particularly interesting that the discontinuity of the shear stress is rather well reconstructed, in comparison to the reconstruction of Legrand et al. (2010). In Figure 19, it is interesting to note that the reconstruction of the shear stress can be considerably improved by using an acquisition of the input signal over two cycles instead of only one (i.e $N_{m}=2000$ ). The discontinuity is indeed very well reconstructed. In this case, the truncation is done at the 1029th harmonic for $\sigma_{r r}$ (and at the 969th for $\sigma_{r \theta}$ ). 


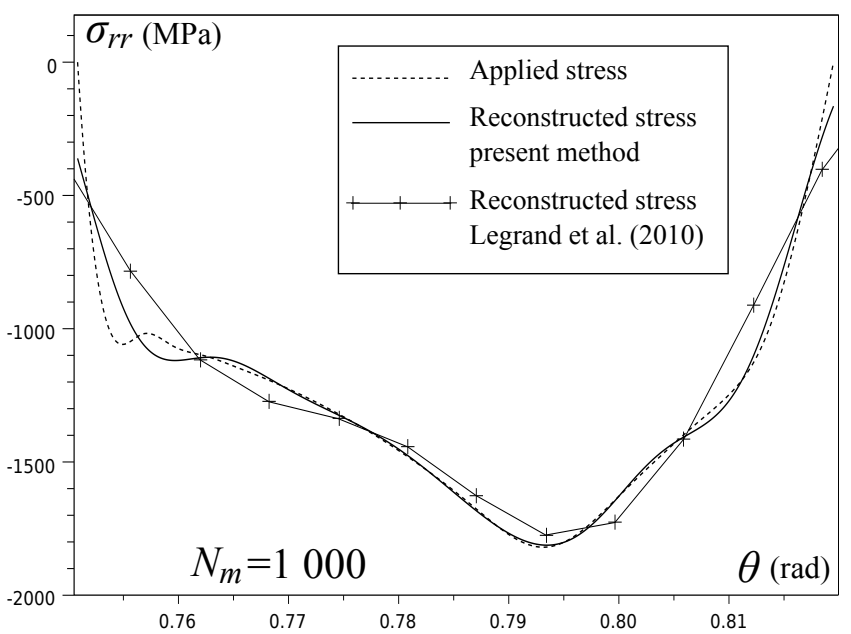

Figure 17: Results for cold rolling without noise, $\sigma_{r r}$

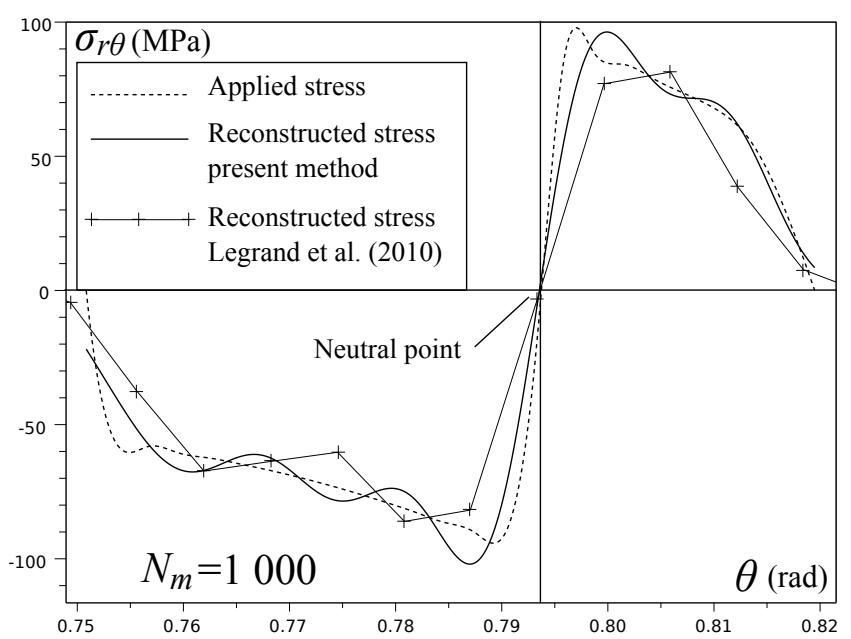

Figure 18: Results for cold rolling without noise, $\sigma_{r \theta}$

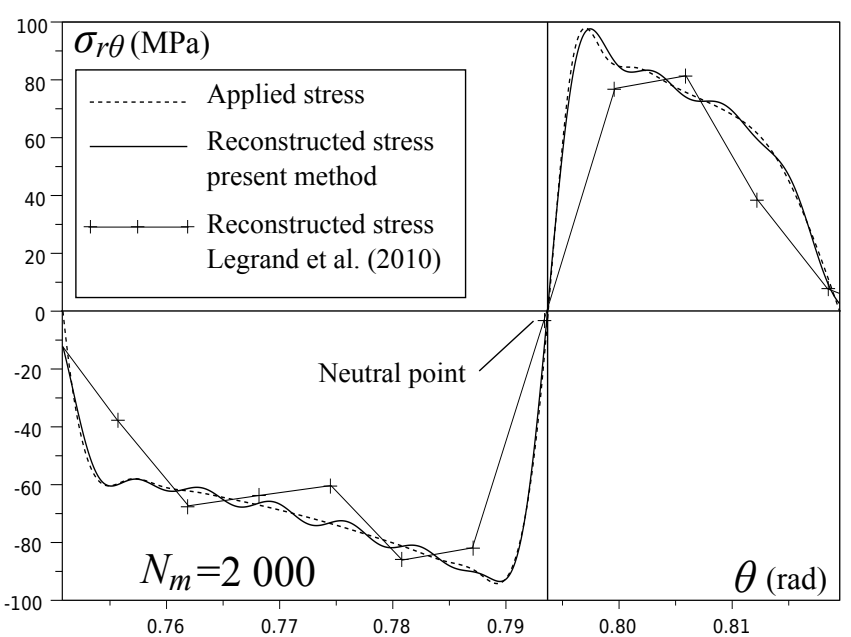

Figure 19: Results for cold rolling without noise, $\sigma_{r}$ 


\begin{tabular}{|l|c|c|c|}
\hline & $\begin{array}{c}\text { Legrand et al. (2010) } \\
(r r / r \theta)\end{array}$ & $\begin{array}{c}\text { Present study } \\
(r r / r \theta)\end{array}$ & $\begin{array}{c}\text { Present study } \\
(r r / r \theta)\end{array}$ \\
\hline$R_{d}(\mathrm{~mm})$ & 200 & 200 & 200 \\
\hline$R_{c}(\mathrm{~mm})$ & 197 & 197 & 197 \\
\hline$N_{t}$ & 600 & $(568 / 534)$ & $(1029 / 969)$ \\
\hline$N_{m}$ & 1000 & 1000 & $\mathbf{2 0 0 0}$ \\
\hline$N_{i n v}$ & 1200 & 0 & 0 \\
\hline$\epsilon(\%)$ & $(8.6 / 26)$ & $(4.14 / 13.20)$ & $(1.83 / 2.64)$ \\
\hline CPU time (s) & $\simeq 2400$ & $\simeq 0.07$ & $\simeq 0.07$ \\
\hline
\end{tabular}

Table 6: Cold rolling summary

\subsubsection{Temper-rolling}

Legrand et al. (2010) show that a reconstruction is not possible for temper-rolling conditions because of the very small length of the roll gap. Indeed, the authors need to calculate the input signal at $1 \mathrm{~mm}$ from the surface of the roll, which is technologically almost impossible. The authors considered three cycles of acquisition at a rotation speed of 1 cycle/second (i.e., $N_{m}=3000$ ). The results presented in Figures 20 and 21 are produced with an input signal calculated at $2 \mathrm{~mm}$ from the surface of the roll, which is a distance that is technologically possible through the insertion of fibre optics. The truncation is done at the 1605th harmonic for $\sigma_{r r}$ (and at the 1371th for $\left.\sigma_{r \theta}\right)$. The results in Figures 20 and 21 show that the new inverse method ( $2 \mathrm{~mm}$ from the surface of the roll) is as accurate as the computation of Legrand et al. (2010) (1 mm from the surface of the roll). Therefore, the new inverse method is more powerful than the older one.

To improve the reconstruction of shear stress, it is possible to consider the acquisition on five cycles instead of three. The resolution becomes $N_{m}=5000$. In this case, the truncation is done at the 2487th harmonic for $\sigma_{r r}$ (and at the 2128th for $\sigma_{r \theta}$ ). Figure 22 shows that the reconstruction is excellent. Moreover, the computation time is extremely reduced compared to the computation time obtained by Legrand et al. (2010).

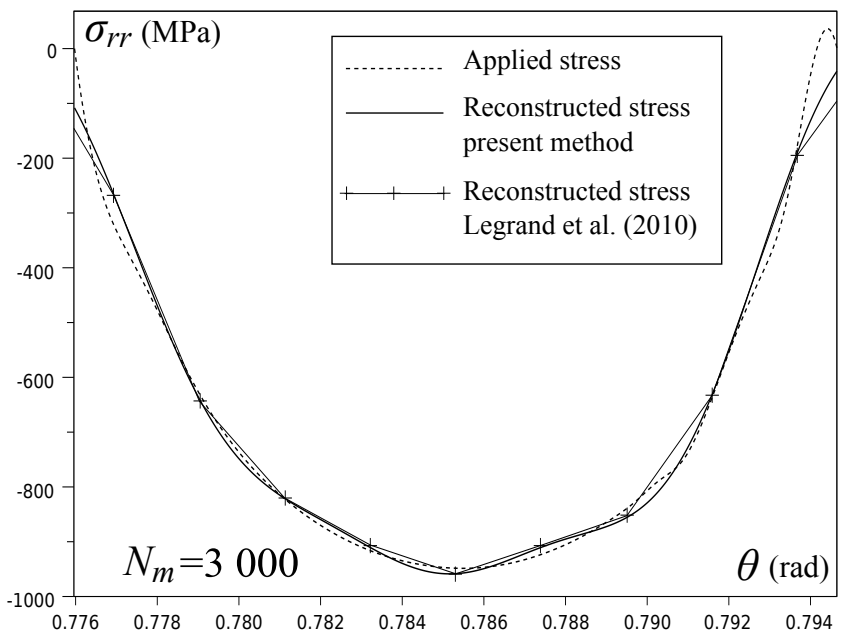

Figure 20: Results for temper-rolling without noise, $\sigma_{r r}$ 


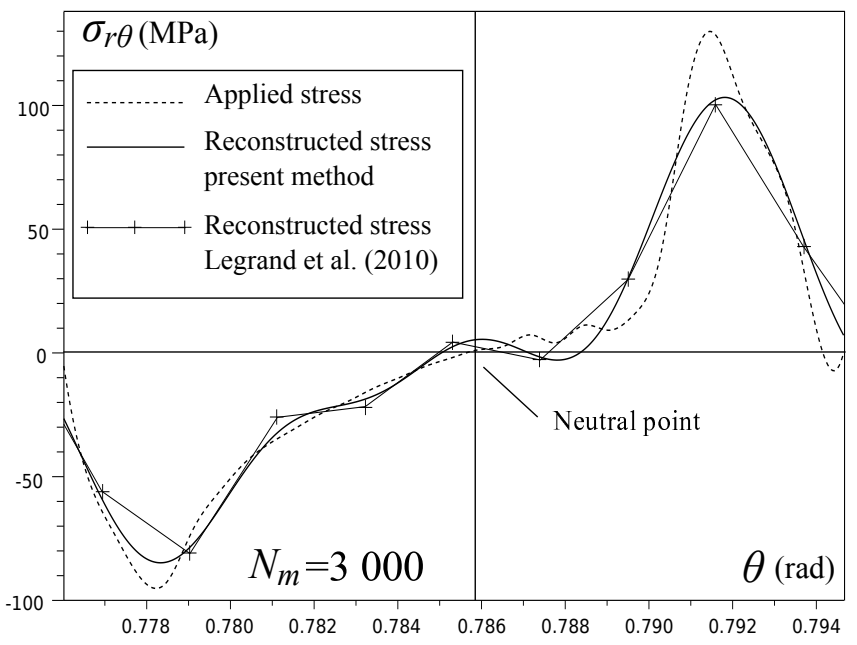

Figure 21: Results for temper-rolling without noise, $\sigma_{r \theta}$

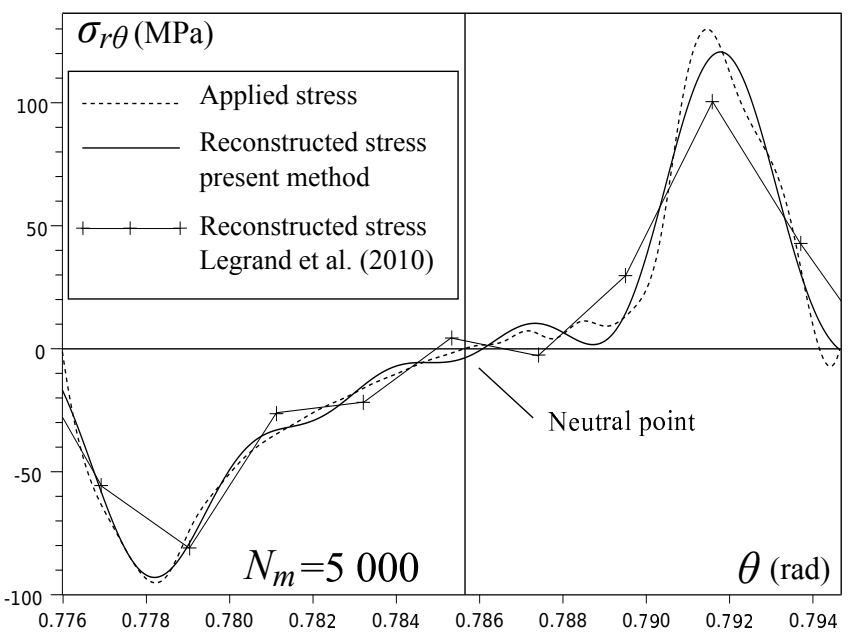

Figure 22: Results for temper-rolling without noise, $\sigma_{r \theta}$

\begin{tabular}{|l|c|c|c|}
\hline & $\begin{array}{c}\text { Legrand et al. (2010) } \\
(r r / r \theta)\end{array}$ & $\begin{array}{c}\text { Present study } \\
(r r / r \theta)\end{array}$ & $\begin{array}{c}\text { Present study } \\
(r r / r \theta)\end{array}$ \\
\hline$R_{d}(\mathrm{~mm})$ & 257 & 257 & 257 \\
\hline$R_{c}(\mathrm{~mm})$ & $\mathbf{2 5 6}$ & 255 & 255 \\
\hline$N_{t}$ & 1200 & $(1605 / 1371)$ & $(2487 / 2128)$ \\
\hline$N_{m}$ & 3000 & 3000 & $\mathbf{5 0 0 0}$ \\
\hline$N_{i n v}$ & 2400 & 0 & 0 \\
\hline$\epsilon(\%)$ & $(4.3 / 21.6)$ & $(3.23 / 19.38)$ & $(2.48 / 9.81)$ \\
\hline CPU time $(\mathrm{s})$ & $\simeq 4800$ & $\simeq 0.07$ & $\simeq 0.07$ \\
\hline
\end{tabular}

Table 7: Temper-rolling summary

\section{Conclusions}

The inverse method developed in this paper gives very good results for three industrial rolling conditions free from noise, under the assumption of a system of acquisition at quite low frequency (signals measured by fibre 
optics). The measurements are carried out practically with noise. Noise sensitivity will be studied in a future publication by processing experimental data. Thus specific methods will be developed to reduce the influence of noise.

A very important improvement is the simplification of the local measurement system because only one measurement point (fibre optics placed inside the roll at the inner radius) is needed, whereas two local sensors at different radii are needed with the older method. The second major improvement is the possibility to apply the method for very singular signals (temper-rolling conditions), whereas the older method fails. The third major improvement is the computation time of the new method allowing a real-time use of the sensor. Thus, the computation (for 55 points of reconstruction) is performed in approximately 0.07 second with a quadcore $2.8 \mathrm{GHz}$ processor (CPU time displayed by Scilab 5.3). The sensor is designed for industrial use.

The next step in this study is thermal analysis to solve the coupled thermal and elastic problems. This analysis will be done within the framework of European project RFS-PR-08051 and will be published later. Experiments on pilot rolling mills and a test on industrial tools are also scheduled.

\section{References}

Andersen, C., Ravn, B., Wanheim, T., 2001. Development of a commercial transducer for measuring pressure and friction on a model die surface. JMPT 115, 205-211.

Boussinesq, J., 1885. Application des potentiels a l'etude de l'equilibre et du mouvement des solides elastiques. Gauthier-Vallars, Paris.

Ferdinand, P., Magne, S., Laffont, G., Dewynter, V., Maurin, L., Prudhomme, C., Roussel, N., Giuseffi, M., Maguis, S., 2009. Optical Fiber Sensors from Laboratory to Field Trials: Applications and Trends at CEA LIST. FIBER AND INTEGRATED OPTICS 28, 81-107.

Hacquin, A., 1996. Modelisation tridimensionnelle du laminage. Ph.D. thesis. Cemef Ecole des Mines de Paris.

Jeswiet, J., Rice, W., 1982. The design of a sensor for measuring normal pressure and friction stress in the roll gap during cold rollin, in: Tenth north american manufacturing research conference proceedings, pp. 130-134.

Lagergren, J., Arentoft, M., Henningsten, P., Wahneim, T., Jonsson, N., Nylander, J., Ederth, J., 2006. New roll gap measurements of the friction conditions and the normal pressure distribution in cold flat rolling, in: Ninth international steel rolling conference, Paris la defense.

Legrand, N., Lavalard, T., Martins, A., 2010. New concept of friction sensor for strip rolling : theoretical analysis, in: International Congress on Tribology of Material Processes, P Montmitonnet ed, Nice, France.

Liu, C., Tieu, A., Ma, B., Jiang, Z., 2002. Friction measurement in hot rolling of steel, in: 44th MWSP Conference, Orlando.

Meierhofer, D., Stelson, K., 1987. Measurement of the interfacial streses in rolling using the elastic deformation of the roll. Journal of engineering for industry 109, 362-369.

Montmitonnet, P., Stephany, A., Cassarini, S., Ponthot, J., Laugier, M., Legrand, N., 2007. Modeling of metal forming lubrication by o/w emulsions, in: Int. Conf. Trib. Mat. Proc., Yokohama. pp. 85-90.

Muskhelishvili, N., 2008. Singular integral equations : boundary problems of function theory and their application to mathematical physics. Dover, New York. pp. 316-322. First edition (1953).

Stelson, K., 1983. A new method to measure normal pressure and frictional stresses in the roll gap during cold rolling, in: Eleventh north american metalworking research conference proceedings, pp. 259-264. 


\section{List of Figures}

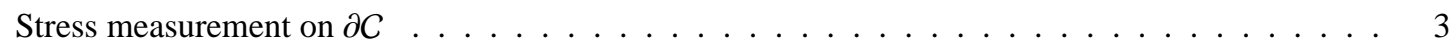

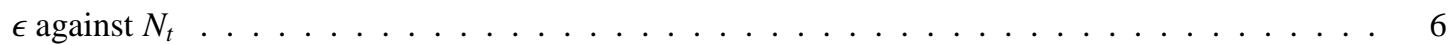

Reconstruction for cold rolling conditions with $N_{m}=1000$ and $N_{t}=100 \ldots \ldots$. . . . . . 7

Reconstruction for cold rolling conditions with $N_{m}=1000$ and $N_{t}=544 \ldots \ldots \ldots$. . . . 8

Reconstruction for cold rolling conditions with $N_{m}=1000$ and $N_{t}=700 \ldots \ldots$. . . . . . . 8

$N_{t}$ vs. $N_{m} \mathcal{S}^{\beta} \ldots \ldots \ldots \ldots \ldots \ldots \ldots \ldots \ldots \ldots \ldots$

$\epsilon$ vs. $N_{s}$ for normal pressures $\left(\sigma_{r r}\right) \ldots \ldots \ldots \ldots \ldots$

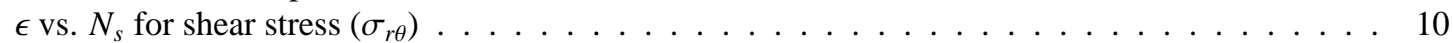

Contact stresses for hot rolling . . . . . . . . . . . . . . . . . . . . 10

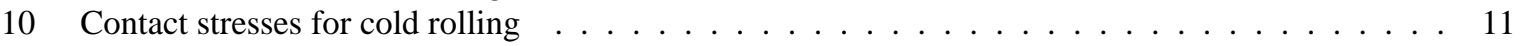

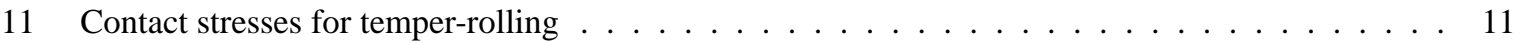

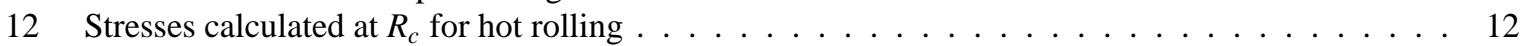

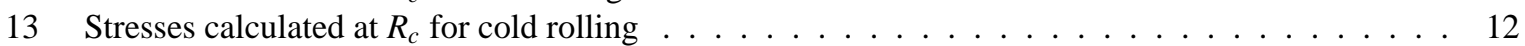

14 Stresses calculated at $R_{c}$ for temper-rolling . . . . . . . . . . . . . . . . . . . . . 12

15 Results for hot rolling without noise, $\sigma_{r r} \ldots \ldots \ldots \ldots \ldots \ldots \ldots$

16 Results for hot rolling without noise $\sigma_{r \theta} \ldots \ldots \ldots \ldots \ldots \ldots \ldots \ldots \ldots$

17 Results for cold rolling without noise, $\sigma_{r r} \ldots \ldots \ldots \ldots \ldots \ldots \ldots$

18 Results for cold rolling without noise $\sigma_{r \theta} \ldots \ldots \ldots \ldots \ldots \ldots \ldots \ldots$

19 Results for cold rolling without noise $\sigma_{r \theta} \ldots \ldots \ldots \ldots \ldots \ldots \ldots$

20 Results for temper-rolling without noise, $\sigma_{r r} \ldots \ldots \ldots \ldots \ldots \ldots \ldots$

21 Results for temper-rolling without noise $\sigma_{r \theta} \ldots \ldots \ldots \ldots \ldots \ldots \ldots \ldots$

22 Results for temper-rolling without noise $\sigma_{r \theta} \ldots \ldots \ldots \ldots \ldots \ldots$

\section{List of Tables}

Nomenclature ............................... 3

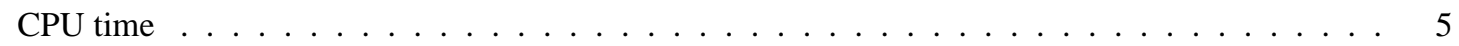

Optimal $N_{t}$ for normal pressure $\ldots \ldots \ldots \ldots \ldots \ldots \ldots \ldots$

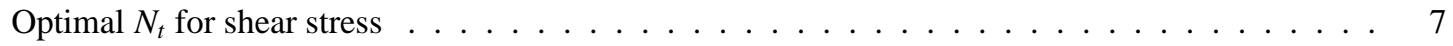

Hot rolling summary . . . . . . . . . . . . . . . . . . . . . . . . 14

Cold rolling summary . . . . . . . . . . . . . . . . . . . . . . 16

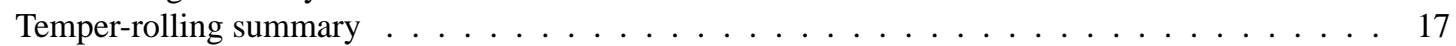

